\title{
The Fabry Family Determined as a Result of the Screening of the Transplanted Patients: A Single-Center Screening
}

\author{
Özgür Can ${ }^{1}$, ๑ Süleyman Baş², @ Melike Betül Öğütmen ${ }^{3}$
}

${ }^{1}$ Department of Nephrology, Bitlis Tatvan State Hospital, Bitlis, Turkey

${ }^{2}$ Department of Internal Medicine Clinic, University of Health Sciences Turkey, Hamidiye Faculty of Medicine, Haydarpaşa Numune Health Application and Research Center, Istanbul, Turkey

${ }^{3}$ Department of Nephrology, University of Health Sciences Turkey, Hamidiye Faculty of Medicine, Haydarpaşa Numune Health Application and Research Center, Istanbul, Turkey

\begin{abstract}
Introduction: Fabry disease (FD) is an X-linked lysosomal storage disorder that arises from a decreased activity of a-galactosidase A. With this study, we evaluated an FD family, which was detected after the screen of transplanted patients.

Methods: We were able to screen 200 transplanted patients at the University of Health Science, Haydarpasa Numune Training and Research Center. a-Gal A activity was used for screening of the male patients. Gene analysis was performed for all female transplanted patients.

Results: Among 200 patients, one 35 years old female patient had a genetic mutation, which was c.376A>G ( $p=S 126 \mathrm{G})$ heterozygous. She received a renal kidney from her sister in 2015. Genetic analysis of this female donor also revealed the same genetic variation. Starting with this index patient, we communicate with available 38 family members. Among these family members, the genetic analysis was performed to 22 family members. Twelve and 10 family members had negative and positive results, respectively. We could not communicate with 12 family members. Only one male family member had positive result and was the nephew of the index case.

Discussion and Conclusion: Eleven family members had positive results for genetic analysis. An 87 years old aunt showed the asymptomatic nature of the disease. Again, the family had only one male member with the mutation.

Keywords: Fabry disease; screening; transplantation.
\end{abstract}

Fos abry disease (FD) is an X-linked lysosomal storage disorder that arises from a decreased activity of a-galactosidase $A$ ( $a-G a l$ A), which leads to progressive accumulation of globotriaosylceramide, and its derivatives in a wide range of cells throughout the body ${ }^{[1]}$. Cardiovascular, neurologic, renal and other organ systems involvements result in morbidity and mortality in patients with $\mathrm{FD}[2,3]$

The treatment of the FD is enzyme replacement treat- ment (ERT) and was shown to have benefits in both transplanted and non-transplanted FD patients. A study conducted by Ersözlü et al. ${ }^{[4]}$ reported superior patient and graft survival rates in renal transplant patients compared to the studies from the pre-ERT studies conducted by Ojo and Inderbitzin et al. ${ }^{[5,6]}$ On the other hand, the rate of delayed diagnosis in FD remains excessively high. There are also living kidney donations within families with un-

Correspondence (iletişim): Özgür Can, M.D. Tatvan Devlet Hastanesi, Bitlis Tatvan Karayolu Üç Yol Mevkii Tatvan, 34000 Bitlis, Turkey Phone (Telefon): +90 5076681344 E-mail (E-posta): canozgur62@hotmail.com 
recognized FD relatives, which is an important problem that should be resolved ${ }^{[7,8]}$. From these standpoints, including better graft-patient survival with ERT, delayed diagnosis of FD and undesirable results of transplantations that were carried out within families forced us to screen transplanted patients in our hospital. In this study, we aimed to evaluate an FD family, which was determined as a result of the screening of the transplanted patients in our hospital.

\section{Materials and Methods}

Until 2017, approximately 700 patients were transplanted at the University of Health Science, Haydarpasa Numune Training and Research Center. Among these patients, we only achieved communication with 200 patients and communicated patients were requested to come to the hospital for testing. As there was no communication data for the remaining patients, these patients could not be reached. Written informed consent was obtained from all patients included in this study. Ethics committee approval was received from the University of Health Science, Haydarpasa Numune Training and Research Center's Ethics Committee.

For male patients, the enzyme test (a-Gal A activity) was used for screening. GLA gene mutation analysis was performed to all transplanted female patients and male patients with a-Gal A activity lower than three micromol/L/h. Plasma globotriaosylsphingosine (lyso-GL-3) levels were measured from patients with positive genetic analysis.

Patients with mutations were evaluated for signs, symptoms related to FD. Cardiology, neurology and ophthalmology consultations were conducted. Echocardiography, cranial magnetic resonance imaging and electromyography were carried out to all patients with mutations.

The Sanger sequencing method was used for genetic analysis. a-Gal A activity testing was carried out to all patients with mutations. Because 27 years old female nephew had lower enzyme activity, fluorimetric analysis of enzyme level was performed by Centogene Laboratory. Lyso-GL-3 level of all patients except recipient and one 46 years old female sister were measured with liquid chromatography-mass spectrometry at Centogene Laboratory in Germany. The normal value of this test was $\leq 1.8 \mathrm{ng} / \mathrm{mL}$. Blood samples of these two patients (donor and recipient) were also analyzed for lyso-GL-3 at ARCHIMED Life Science GmbH laboratory in Vienna and the normal value was $\leq 3.5 \mathrm{ng} / \mathrm{mL}$. The method used was a tandem mass spectrometry.

\section{Results}

Among a total of 200 transplanted patients, only one female patient had genetic variations concerning FD. This 35 years old female patient revealed c.376A $>G(p=S 126 G)$ heterozygous mutation. The cause of chronic kidney disease was reported in native renal biopsy as hypertensive nephropathy and chronic pyelonephritic changes. She had preemptive kidney transplantation donated by her sister in 2015. Tacrolimus, mycophenolate mofetil and prednisolone triple treatments were instituted after the renal transplantation. The serum creatinine was $0.86 \mathrm{mg} / \mathrm{dL}$ and urine analysis was normal. Cardiology, ophthalmology, dermatology and neurology consultations yielded no results in favor of FD. Family history was unremarkable for FD. Her a-Gal A activity was normal, and the result was $8 \mathrm{mmol} / \mathrm{L} / \mathrm{h}$.

Starting with this index patient, family members underwent evaluation. Among 38 family members not including the index case, genetic analysis obtained from 22 family members. Four of the family members were deceased who were the index case's father, one uncle, one aunt and one cousin. Twelve family members had negative results and the other 10 members had positive results for genetic analysis. Only one male member of the family had a positive result for genetic analysis and was the nephew of the index case. We could not have communicated with twelve family members, so we could not take blood samples for analysis. The demographic, clinical and laboratory parameters of the index and screened 15 family members are shown in Table 1. Family members with incomplete data because of living in other cities and death family members were not included to the Table. The family pedigree is also shown in Figure 1.

History of the father of index case consisted of death due to $\mathrm{HCC}$. The daughter of the index case revealed negative genetic analysis. All siblings of the index case were screened, and all male siblings revealed negative genetic analysis. All the sisters revealed positive results for genetic analysis. The children of the first sister revealed negative genetic analysis. One female and one male children of the second sister revealed positive genetic analysis. The children of the third sister revealed positive genetic analysis for the female child and negative genetic analysis for the male child. We also screen the one-year-old male child who was the son of the index patient's nephew and obtained negative result for genetic analysis. The index case has three aunts and two uncles. Among these, one aunt and one uncle were deceased, we could not learn the cause of deaths and we could not screen their children. The second uncle and 









Figure 1. A pedigree of a family with individuals having fabry mutation.

aunt revealed negative results for the genetic analysis. The third aunt, who was 87 years old and lived in Trabzon, also revealed positive mutation. One of her sons died because of colon cancer, and we could not screen her second female child. The deceased son has four children; three of them revealed the positive results for genetic analysis and the other child did not.

Regarding enzyme results, only one female family member who was 27 years old and nephew of the index case revealed decreased enzyme levels at two different measurements. The results were $2.2 \mu \mathrm{mol} / \mathrm{L} / \mathrm{h}$ and $14.6 \mu \mathrm{mol} / \mathrm{L} / \mathrm{h}$ and should be higher than $2.5 \mu \mathrm{mol} / \mathrm{L} / \mathrm{h}$ and $\geq 15.3 \mu \mathrm{mol} /$ $L / h$, respectively.

Regarding lyso-GL-3 results, only the donor and the index case increased lyso-GL-3 levels. The donor had one measurement, and the result was $3.8 \mathrm{ng} / \mathrm{mL}$ (should be $\leq 3.5$ $\mathrm{ng} / \mathrm{mL}$ ). The index case also had two measurements and one case was within the normal range ( $3 \mathrm{ng} / \mathrm{mL}$, should be $\leq 3.5 \mathrm{ng} / \mathrm{mL}$ ), the other case was higher than the upper limit ( $3 \mathrm{ng} / \mathrm{mL}$, should be $\leq 1.8 \mathrm{ng} / \mathrm{mL}$ ).

\section{Discussion}

Several studies were conducted to screen FD in CKD, dialysis and renal transplant patients. A study conducted in Turkey by Türkmen et al. ${ }^{[9]}$ investigated the prevalence of the FD in 313 eligible CKD patients not receiving renal replacement therapy, and the prevalence of FD in CKD patients was $0.95 \%$. The first screening study in hemodialysis patients in Turkey was carried out by Kalkan et al. ${ }^{[10]}$ and they evaluated 808 male patients but not female patients. The prevalence of a-Gal A deficiency in Turkish males receiving hemodialysis was $0.24 \%$. In another study conducted by Sayilar et al., ${ }^{[11]}$ GLA genotyping confirmed the diagnosis of the FD in five (0.3\%) patients with low a-Gal A activity among 1527 dialysis patients at 17 dialysis centers across Bursa province in Turkey. Yılmaz et al. ${ }^{[12]}$ evaluated renal transplant patients and found eight variations $(0.73 \%)$ among 1095 patients. In our study, only one patient was detected to have an FD mutation among 200 transplanted patients $(0.5 \%)$.

The threshold for a-Gal A activity in our study for male patients was three micromol/L/h. We used this threshold because the lower threshold used in the study of Türkmen et al. ${ }^{[9]}$ missed some male patients despite FD symptoms and genetic and histological evidence of FD. It should also be noted that a significant number of affected FD heterozygotes may have $a-G L A$ activities that fall within the normal range, rendering enzyme diagnosis unreliable. ${ }^{[13,14]}$ Thus, we carried out the genetic analysis to all family members and all female transplanted patients not regarding enzyme levels. The mutation found in our study was c.376A>G $(p=S 126 G$ ) heterozygous, and it is reported as unknown clinical significance in Clinvar (rs149391489). Only one 23 years old male patient had the same mutation and he was free of signs and symptoms related to FD and investigations yielded no pathologic findings.

Disease presentation in female heterozygotes may be as severe as in males although women are more likely to remain asymptomatic for long times. Regarding the index case, a native renal biopsy was reported as hypertensive nephropathy, chronic pyelonephritic changes and no evidence of FD was detected by this biopsy. The renal biopsy sample was evaluated using light microscopy, and EM review could not be performed. This index case, apart from renal involvement, had also numbness of the hands. Her lyso-GL-3 level was also high in one of the two measurements. The donor also had symptoms, such as numbness of hands, burning of feet, electric-shock-like pain in feet, and her lyso-GL-3 level was higher. The other female patient had leg pain when climbing stairs and her enzyme analysis revealed lower enzyme levels at two measurements. The last female patient we evaluated had proteinuria and numbness of the hands but the normal result for lyso-GL-3. Another family member who was 87 years old was alive, 
and no serious complication was seen in this patient.

It is also important to decide if the patient will require ERT or not. For patients with uncertain diagnosis, electron microscopic evaluation to demonstrate globotriaosylceramide accumulation on affected organs would be helpful. On the other hand, plasma lyso-GL-3 is reported to correlate with disease severity and is used to make a treatment decision. ${ }^{[15]}$ We started ERT to our patients with high lysoGL-3 level both to the recipient and to the donor. It should be kept in mind that mutations, such as D313Y, A143T may not result in increased lyso-GL-3 levels and normal values, cannot exclude FD. ${ }^{[16]}$

Our limitation is screen of the 200 of 700 transplanted patients in our hospital. EM review could not be performed for renal biopsy. In addition to these limitations, an effort with screening transplant patients yielded clinical data

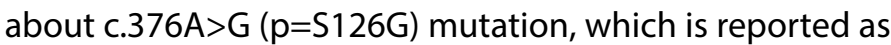
unknown clinical significance in Clinvar.

In conclusion, only one patient was diagnosed among 200 transplanted patients, and starting with this index case, a total of 11 family members with the positive mutations were found. Among these patients, an 87 years old female family member with no serious complication was detected. The patient proves the asymptomatic nature of the disease. However, although c.376A $>\mathrm{G}(\mathrm{p}=\mathrm{S} 126 \mathrm{G})$ mutation is known as unknown clinical significance in Clinvar, some of our patients had symptoms related to FD and ERT started.

Ethics Committee Approval: University of Health Science, Haydarpasa Numune Training and Research Center's Ethics Committee.

Peer-review: Externally peer-reviewed.

Authorship Contributions: Concept: M.B.Ö.; Design: M.B.Ö., Ö.C., S.B.; Data Collection or Processing: M.B.Ö., Ö.C., S.B.; Analysis or Interpretation: M.B.Ö., Ö.C.; Literature Search: Ö.C.; Writing: Ö.C.

Conflict of Interest: None declared.

Financial Disclosure: The authors declared that this study received no financial support.

\section{References}

1. Germain DP. Fabry disease. Orphanet J Rare Dis 2010;5:30.

2. Nakao S, Takenaka T, Maeda M, Kodama C, Tanaka A, Tahara M, et al. An atypical variant of Fabry's disease in men with left ventricular hypertrophy. N Engl J Med 1995;333:288-93. [CrossRef]
3. MacDermot KD, Holmes A, Miners AH. Anderson-Fabry disease: clinical manifestations and impact of disease in a cohort of 60 obligate carrier females. J Med Genet 2001;38:769-75.

4. Ersözlü S, Desnick RJ, Huynh-Do U, Canaan-Kühl S, Barbey F, Genitsch V, et al. Long-term Outcomes of Kidney Transplantation in Fabry Disease. Transplantation 2018;102:1924-1933.

5. Ojo A, Meier-Kriesche HU, Friedman G, Hanson J, Cibrik D, Leichtman $A$, et al. Excellent outcome of renal transplantation in patients with Fabry's disease. Transplantation 2000;69:23379. [CrossRef]

6. Inderbitzin D, Avital I, Largiadèr F, Vogt B, Candinas D. Kidney transplantation improves survival and is indicated in Fabry's disease. Transplant Proc 2005;37:4211-4. [CrossRef]

7. Popli S, Molnar ZV, Leehey DJ, Daugirdas JT, Roth DA, Adams $M B$, et al. Involvement of renal allograft by Fabry's disease. Am J Nephrol 1987;7:316-8. [CrossRef]

8. Odani K, Okumi M, Honda K, Ishida H, Tanabe K. Kidney transplantation from a mother with unrecognized Fabry disease to her son with low a-galactosidase A activity: A 14-year followup without enzyme replacement therapy. Nephrology (Carlton) 2016;21:57-9. [CrossRef]

9. Turkmen K, Guclu A, Sahin G, Kocyigit I, Demirtas L, Erdur FM, et al. The Prevalence of Fabry Disease in Patients with Chronic Kidney Disease in Turkey: The TURKFAB Study. Kidney Blood Press Res 2016;41:1016-24. [CrossRef]

10. Kalkan Uçar S, Sozmen E, Duman S, Başçi A, Çoker M. Alphagalactosidase $A$ activity levels in Turkish male hemodialysis patients. Ther Apher Dial 2012;16:560-5. [CrossRef]

11. Sayilar El, Ayar Y, Yavuz M. Prevalence of Fabry disease among Turkish dialysis patients: Data from hemodialysis centers in Bursa province. Clin Nephrol 2016;85:165-72. [CrossRef]

12. Yılmaz M, Uçar SK, Aşçı G, Canda E, Tan FA, Hoşcoşkun C, et al. Preliminary Screening Results of Fabry Disease in Kidney Transplantation Patients: A Single-Center Study. Transplant Proc 2017;49:420-4. [CrossRef]

13. Gal A, Hughes DA, Winchester B. Toward a consensus in the laboratory diagnostics of Fabry disease - recommendations of a European expert group. J Inherit Metab Dis 2011;34:509-14.

14. Dajnoki A, Fekete G, Keutzer J, Orsini JJ, De Jesus VR, Chien $\mathrm{YH}$, et al. Newborn screening for Fabry disease by measuring GLA activity using tandem mass spectrometry. Clin Chim Acta.2010;411:1428-31. [CrossRef]

15. Young E, Mills K, Morris P, Vellodi A, Lee P, Waldek S, Winchester B. Is globotriaosylceramide a useful biomarker in Fabry disease? Acta Paediatr Suppl 2005;94:51-4. [CrossRef]

16. Smid BE, van der Tol $L$, Biegstraaten $M$, Linthorst $G E$, Hollak $C E$, Poorthuis BJ. Plasma globotriaosylsphingosine in relation to phenotypes of Fabry disease. J Med Genet 2015;52:262-8. 